\title{
Las marcas de la formación virtual en la configuración de las identidades docentes
}

\section{Professora e pesquisadora da Universidade de Buenos Aires \\ Laura Valeria Marotias \\ Mestranda em Ciências Sociais pela FLACSO \\ Silvia Finocchio \\ Doutora em Ciências Sociais pela FLACSO}

\section{Resumen}

El propósito de este artículo es presentar y analizar los modos de construcción y reconstrucción de las subjetividades y las identidades docentes en espacios virtuales de formación, atendiendo a relatos e interacciones tanto formales como informales. Considerando que los elementos que participan en la construcción del yo y del nosotros cambian junto con los contextos culturales, nos interesa indagar qué sucede con las subjetividades e identidades docentes en el contexto actual, en el que asistimos al tránsito de un paradigma introdirigido hacia uno alterdirigido producto, entre otros factores, de cambios tecnológicos que han multiplicado los canales de comunicación y los espacios donde mostrarse.

Palabras-clave: espacios virtuales; identidades docentes; subjetividades.

\begin{abstract}
The objective of this article is to present and analyse the different ways of construction and reconstruction of subjectivities and identities of teachers that participate in learning virtual environments, paying attention to the narratives and interactions both formal and informal. Considering that the elements that participates in the construction of subjectivities change in each cultural context, we are interested in asking what happens with teacher's identities in the current context characterized by the transition from a paradigm centered in the privacy of the own identity to another, based on the exhibition of it. This change is a result, among other causes, of the technological development that multiply the ways of communication and the environments where people can show themselves.
\end{abstract}

Keywords: virtual environments; identities of teachers; subjectivities. 

puesto al modelo propio de la Modernidad, profundamente volcado hacia lo interior, lo íntimo y lo privado y expresado, por ejemplo, en la proliferación de diarios íntimos, confesiones y otros escritos "del yo", producidos al abrigo de habitaciones privadas, en donde la soledad era el estado que se requería para acceder al conocimiento de sí, asistimos hoy a un escenario en el cual la construcción de la subjetividad y de la identidad profesional está atravesada por la idea de la visibilidad, gestada en torno al desarrollo de los nuevos artefactos tecnológicos.

Las pantallas - de la computadora, del televisor, del celular, de la cámara de fotos o de lo que sea - expanden el campo de visibilidad, ese espacio donde cada uno se puede construir como una subjetividad alterdirigida. La profusión de pantallas multiplica al infinito las posibilidades de exhibirse ante las miradas ajenas para, de ese modo, volverse un yo visible. (Sibilia, 2008, p. 130)

En este contexto, nos interesa investigar las marcas que estos cambios en la forma de producir y expresarse dejan en los docentes y se manifiestan en todos los contextos en los que participan, especialmente, en cursos de formación docente virtuales, donde cumplen el rol de alumnos.

Para abordar tales modos de construcción y reconstrucción de las subjetividades y las identidades analizaremos los Cafés, foros de interacción informal entre alumnos, y los espacios destinados a las presentaciones personales de los cursos de formación docente del área de Educación del campus virtual de FLACSO Argentina (http://virtual.flacso.org.ar). Consideramos que es en esos espacios, a través de la escritura de sí, donde los docentes, ponen en juego los elementos que constituyen su propia subjetividad así como rasgos de la identidad profesional.

Particular interés tendrán las cuestiones que permitan pensar cómo se entraman en las subjetividades e identidades docentes las relaciones entre la cultura que aportan las nuevas tecnologías con la cultura académica y la cultura empírica de los enseñantes. 


\section{Los espacios virtuales}

Las propuestas de formación virtual de posgrado que ofrece FLACSO Argentina asociados a la cuestión educativa son diversas y abarcan temáticas tales como: el curriculum, la lectura y la escritura, las nuevas tecnologías, la enseñanza de las ciencias, la gestión educativa, las teorías del aprendizaje, entre otros.

Los perfiles profesionales de los alumnos de estos cursos se enmarcan en el campo de la docencia y la educación, pero las especialidades de cada grupo son diferentes en función de los cursos elegidos. Sin embargo, podemos encontrar ciertas regularidades que consideramos están relacionadas con su formación e identidad docente, más allá de su ámbito de desempeño profesional específico.

En ese sentido encontramos que, de los variados espacios que posee un curso virtual en la plataforma de FLACSO Argentina, algunos de ellos muestran estos rasgos comunes al tratarse de lugares en los que la subjetividad se manifiesta de manera más visible. Estos espacios son los foros de presentación y el foro llamado Café.

En los foros de presentación de cada posgrado, los colegas hacen un breve relato de sí mismos dirigido a quiénes serán sus compañeros de curso, sus tutores y sus profesores, con quienes compartirán una comunidad virtual de enseñanza-aprendizaje. Es la primera construcción de sí mismos que realizan para interactuar con los demás.

Por otra parte, el foro Café es un espacio de intercambio social libre, sin consignas previas y del que sólo participan los alumnos. Una diferencia técnica fundamental entre ambos, que deviene de una decisión pedagógica, es que los alumnos, en el Café, pueden abrir nuevos hilos de discusión, mientras que en el resto de los foros del curso (temáticos, de producción colaborativa, de consultas, de presentación), son los profesores quiénes inician los temas de discusión y los alumnos responden a esas consignas, generándose así el intercambio de ideas, reflexiones y consultas tanto hacia los profesores como entre los mismos colegas.

Los Cafés de los cursos aportan al fortalecimiento de las relaciones 
personales entre colegas al interior del campus. A pesar de no integrar la currícula de los cursos, los Cafés, cumplen una función central en la educación virtual estrechando los vínculos personales entre los miembros de la comunidad virtual de cada curso constituyéndose en espacios de construcción de lazos entre colegas que atraviesan una experiencia de aprendizaje común.

\section{Nosotros y los otros: los alumnos}

Recorriendo los distintos cursos hemos podido observar que existe una importante identificación entre el nosotros constituido por "los docentes" y el ellos integrado por "los alumnos", la mayoría de las veces adolescentes y niños. Esta relación se percibe de formas diferentes, algunas veces asumiendo la responsabilidad por las problemáticas en materia de aprendizaje que presentan los alumnos y tratando de revertirlas en una ida y vuelta entre ambos, y otras responsabilizando a agentes que consideran externos a la escuela, como la televisión, Internet y todo lo que implica: blogs, fotologs, música, redes sociales entre adolescentes.

Esto se ve más claramente en lo que tiene que ver con la cultura letrada, que es considerada, por los docentes, como el principal vehículo de formación y conocimiento. Así, en el curso de Escritura, Lectura y Educación, encontramos como preocupación central el intento por despertar en los alumnos el interés por la lectura y la escritura, considerada, en la mayoría de los casos, como lectura de libros. Así, aparecen testimonios como el siguiente, correspondiente a la cohorte 2008 del mencionado curso:

Soy profesor de Ciencias Sagradas y Filosofía y me desempeño como catedrático en dos IFD del interior de la provincia.

Hay algo muy fuerte que me sirvió de motivación para empezar este trayecto, el desacostumbramiento de la lectura que va en aumento año tras año, lo que lleva a que cada vez los jóvenes escriban menos y que lo que escriben lo "escriban mal". Pero esta situación lleva a plantearme sí serán ellos los que no saben escribir ó sí seré yo quien no sabe interpretar 
sus formas de escritura, que a lo mejor son propias de estos tiempos. En fin, alguien tiene que entender al otro, porque sino nuestra incomunicación se agrava cada vez más y más, y las distancias generacionales son cada día más grandes.

Mis expectativas son muchas, y espero poder responder a las exigencias de esta propuesta formativa.

Los saludo a todos.

O el siguiente, correspondiente a una alumna del mismo curso:

Hola a todos. Mi nombre es Luciana y vivo en Concordia, Entre Ríos. Soy licenciada en Letras y tengo a cargo la cátedra Investigación educativa en los profesorados de Inglés y de Lengua.

Advierto, con desánimo, que las dificultades de los alumnos del nivel terciario para leer y escribir son similares a las de los alumnos de la escuela media y, por eso, espero que este curso me permita encontrar nuevas y eficaces herramientas para ayudarlos a mejorar sus habilidades lingüísticas.

Nos mantenemos en contacto. Saludos.

\section{Nosotros y los otros: las tecnologías digitales}

Otro aspecto que hemos podido observar a través del discurso de los propios docentes es, en la mayoría de los casos, cierto temor en relación con las tecnologías digitales. La mayoría de los participantes están realizando un curso virtual por primera vez e ingresan a él como "extranjeros". Aquí se produce un desfasaje entre el contenido de los cursos, todos de posgrado, y el espacio virtual, puesto que consideran lo virtual como el lugar de las nuevas generaciones y en ese sentido se sienten extraños pero, al mismo tiempo, al tratarse de una propuesta educativa, la virtualidad es entendida como un medio para acceder a esa formación a la que de otra forma les hubiera resultado prácticamente imposible llegar, puesto que muchos de los docentes (alumnos en este caso) pertenecen al interior de la Argentina e, inclusive, a otros países de América Latina. Siguiendo a Manuel Castells 
(1995), en un mundo de globalización de las comunicaciones y de flexibilización de los horarios y localizaciones laborales, la educación a través de Internet comienza a vislumbrarse como una herramienta que aporta a la satisfacción de necesidades crecientes de formación. Este tipo de enseñanza y de aprendizaje constituye un nuevo espacio educativo con sus prácticas y trayectorias específicas, las que son ajenas a los propios alumnos virtuales cuando ingresan por primera vez a la educación a través de Internet.

Es así que se percibe una disociación, expresada en el discurso de los docentes, entre las prácticas que los jóvenes y adolescentes mantienen con respecto a las nuevas tecnologías y las que establecen ellos. Esto es muy cierto en la mayoría de los aspectos, sin embargo, en un curso virtual también hay espacios de exposición de sí mismos y de construcción discursiva de la personalidad, pero no son percibidos como tales, o lo son enmarcados en la "seriedad" que representa un curso de posgrado en una institución académica.

Así, podemos observar el siguiente diálogo entre dos alumnos del Diploma Superior de Curriculum y Prácticas escolares en contexto, en el espacio Café:

Flogs, blogs y otras yerbas

de Flavia Ivón Bouza - miércoles, 23 de abril de 2008, 21:33

Estimados compañeros de curso: he leído bastante las opiniones vertidas en el café y heme aquí proponiendo que me cuenten un poco qué piensan sobre el tema de los flogs, blogs, y otros espacios personales tan usados hoy por los adolescentes. Hace unos días recibí por mail la invitación a participar de uno (perteneciente a un familiar - adolescente), allí encontré fotografías personales: con amigos, novio, familia. Me sorprendió particularmente esto de que uno puede "firmar", es decir plasmar su opinión acerca de esas imágenes. Leí bastantes agravios (no sin dificultad para decodificar la ortografía) hacia quienes aparecían en las fotografías. Eso me llevó a pensar en los últimos casos de violencia entre estudiantes tan comunes por estos días. ¿No es interesante cómo esos espacios funcionan? Quienes firman se conocen, se frecuentan, van al 
mismo colegio, sin embargo usan ese espacio para "dialogar". Es raro, ¿no? También me llamó la atención cómo la palabra se sitúa como una "lectura" de las imágenes que se ofrecen ya que quienes las "suben" esperan esas evaluaciones. Los planos de la intimidad se modifican, se reclaman las "lecturas" de los otros sobre la propia vida y la palabra sigue (a pesar de pronósticos desfavorables) teniendo un protagonismo relevante (más allá de los "cambios" por decirlo de un modo sutil que se observan de nuestro idioma, cosa que ¿vendría a demostrar una apropiación de una lengua heredada de quienes ejercen el "poder"?: los adultos en este caso.

Re: flogs, blogs y otras yerbas

de Maria Marcela Godoy - jueves, 24 de abril de 2008, 13:12

Uh Flavia, tocaste un tema que me tiene "preocupada" y "ocupada". En primer lugar porque tengo una hija adolescente que anda en esa "onda". Escucho, leo, entro a "espiar" lo que muestra/n, escribe/n, opina/n... etc.etc. Me hago muchas preguntas al respecto:

- ¿la intimidad?; ¿los límites de la exposición fotográfica?; ¿la valoración del otro? ¿y lo qué escriben?? Hasta dónde...

Por otra parte VIVEN SACÁNDOSE FOTOS... en poses varias, etc.etc. y después la "cuelgan". Como verás es una tecnología que supone varias cuestiones para conversar. bue... será cuestión de ir aprendiendo e intentar acompañar este proceso innovador. Seguimos después? Esto es el comienzo...

En relación con este aspecto, Paula Sibilia (2008), analiza la exhibición de la intimidad a través de Internet y afirma que este fenómeno de "hacerse visible" representa (junto con otros espacios donde se expresa esta misma tendencia), un momento cultural de transición que genera una mutación en las subjetividades. Esa mutación tiene que ver con el cambio en los límites de la intimidad marcado por la Modernidad y la cultura burguesa, para pasar a una construcción de sí mismo basada en la posibilidad de contar con potenciales lectores que funcionen como público para la espectacularización de las vidas comunes.

De acuerdo con lo observado en los discursos de los docentes, ellos también forman parte de esta exhibición de sí mismos a través de Internet, 
pero dentro del marco de un curso virtual. De esta manera, no perciben que, aún con diferencias importantes respecto de los adolescentes, ellos mismos están realizando un relato de sí mismos y una construcción de su subjetividad para mostrarse ante otros. Los límites de esta exposición son mucho más claros que en el caso de los jóvenes ya que, fundamentalmente, el público está formado sólo por sus compañeros de curso. Otro aspecto para ejemplificar estos límites en la exposición tiene que ver con una propuesta del curso de Lectura, escritura y educación, donde se realizó un taller literario a través de un foro, en el que los alumnos (en este caso docentes), debían escribir textos de ficción guiados por sus tutoras. En un primer momento, el taller tenía muy poco movimiento. A raíz de esta situación el equipo docente del curso decidió utilizar seudónimos sólo para este espacio. Esta decisión pedagógica implicó también un trabajo de desarrollo tecnológico. Una vez puesta en marcha la innovación, los textos de ficción comenzaron a aparecer y la participación en el foro del taller literario se hizo cada vez mayor. Esto es un ejemplo claro de hasta dónde puede alcanzar la exposición a través de Internet en personas que no son "nativas" de las tecnologías digitales y que, al mismo tiempo, están realizando un curso virtual y comparten espacios de exhibición y construcción de la imagen de sí mismos, a pesar de que este aspecto no sea percibido tan claramente respecto de sí mismos como cuando lo observan en sus alumnos.

Por otra parte, en el Diploma de Curriculum y prácticas escolares existe un taller de armado de blogs, que tiene como objetivo que los docentes realicen su propio blog a partir de ciertos parámetros que lo enmarcan dentro del género profesional-académico. Se trata de una actividad voluntaria, de la que participa la mitad de la matrícula del curso. La mayoría de ellos aceptaron el desafío de crear su propio blog desde sentimientos relacionados con la emoción por acercarse a un mundo que siempre consideraron ajeno. La propuesta tiende a la alfabetización digital de los docentes de manera explícita; sin embargo, en todos los espacios del campus virtual se está realizando alfabetización digital al mismo tiempo que se accede a los contenidos de cada uno de ellos.

Se trata de una propuesta que tiende a acercar a los docentes y 
alumnos a partir de que los primeros incursionen en el lenguaje y las prácticas digitales, utilizándolas de acuerdo con sus necesidades e intereses. En cuanto a esta relación entre lo social y lo tecnológico orientada a la educación, Franco Berardi (2007, p. 25) afirma que

En la Modernidad el ambiente técnico cultural cambiaba lentamente con el transcurrir del tiempo. Eran necesarias décadas para que la utilización de una técnica pudiera cambiar las formas de pensamiento y las modalidades de acercamiento a la realidad. Cuando entran en escena las tecnologías digitales, las formas de aprendizaje, memorización e intercambio lingüístico se modifican rápidamente, incluso en el marco de una generación.

De ahí que las formas de concebir el tiempo, el espacio y las relaciones sociales estén distanciándose entre docentes y alumnos y sean necesarias estrategias de acercamiento que sólo son posibles a partir de la comprensión de la cosmovisión de la otra parte, especialmente en el ambiente educativo, donde la relación intergeneracional es parte primordial de la transmisión.

En ese sentido, es de especial interés el testimonio de una alumna del taller de blogs que encontró, a partir de la consigna de revisar algunos blogs profesionales propuestos desde la coordinación del taller, una actividad para compartir con sus hijos:

Hola Ana, hola a todos... Soy Laura y me encanta la idea de pensar en armar un blog. Les debo las reflexiones y los comentarios académicos porque quede varada en el blog de Luis Pescetti, vinieron mis hijos a ver qué hacía y terminamos jugando, cantando, bailando y leyendo chistes y fragmentos de cuentos...un encanto. Gracias por el buen momento y más adelante les cuento sobre incursiones más serias en el tema blogs....besos.

En la misma línea, también podemos citar el comentario realizado por otra alumna en el foro de intercambio del taller de blogs del mismo Diploma superior: 
Hola!

La verdad es que me sumo a otro desafió. Me entusiasma pero desde ya me genera temor, es desconocido, y es una experiencia distinta pues mi hija de once añitos tiene su blog donde escribe cuentos y sube fotos. A mí me maravilla verla y leerla.

Aquí soy analfabeta, y espero dejar de serlo, voy a necesitar mucha ayuda y paciencia. En fin he visitado el blog de Pescettiahora voy a seguir recorriendo otros. Allí vamos!! M. de los Angeles.

\section{Nosotros}

A lo largo de este artículo se ha intentado mostrar cómo, a través del discurso de los docentes en determinados espacios de un campus virtual, aparecen las marcas que hacen a su profesión e identidad, más allá de las especificidades profesionales de cada uno de ellos. Así, identificamos a la cultura letrada como el vehículo principal de conocimiento, aunque con ciertas aperturas, que incluyen a la televisión e Internet. Pero siempre en un plano secundario.

Por otra parte, existen espacios en los que la exposición de la subjetividad es especialmente fuerte, como en el caso del Café, o del Taller de escritura y que, de acuerdo con las características del perfil docente, estos espacios muchas veces operan como lugares de puesta en común de problemas, reflexiones y experiencias surgidos en el contexto del aula. Como en el caso de este ejemplo:

Soy María Inés López [...] siempre tuve interés por los procesos de construcción de la Lectura y la Escritura en los niños. Desde mi formación como Profesora en Letras, este interés se incrementó. Mas aún cuando comencé a trabajar en el Polimodal y encontré tantas dificultades en los adolescentes para acercarse a la lectura, por lo menos a la que le proponíamos desde la escuela. Hoy me preocupa esta "crisis" y me pregunto por las otras "lecturas" que los chicos hacen, porque no es cierto que no leen, en realidad, leen otras cosas que no son las que los docentes 
pretendemos. El año pasado, un alumno muy moderno, con un vestir muy particular, que se llevaba mal con todos los profesores, que no le interesaban mucho mis clases, se acercó y me preguntó si le podía prestar libros de poesía de algún autor surrealista. Le acerqué alguno y no sólo le gustó sino que compartía conmigo sus interpretaciones cada vez que me veía. Bueno, puedo contar, en otro momento, mucho más. Hasta la próxima comunicación. María Inés

Por otra parte, a través de la educación virtual, las prácticas de los estudiantes (docentes en el caso analizado) se transforman, ya que ellos mismos leen y escriben como principal opción comunicativa, de aprendizaje y de estudio. Al mismo tiempo, se les proponen nuevos modos de leer, ampliando generalmente la circulación de textos, ofreciendo rutas de lectura, acercándolos a las bibliotecas virtuales y planteándoles intercambiar por escrito a partir de lo leído. Los estudiantes leen más, leen en diversos géneros y leen en distintos soportes. Leen clases virtuales, bibliografía, foros e intercambios con profesores y compañeros. Leen no sólo de la pantalla sino también del papel, y por eso la lectura se transforma en formas disformes, ya que en gran parte se imprime, según nuestras indagaciones. Su escritura convive también entre diversos géneros, más cercanos a lo oral, en los intercambios, y más alejados, en las propias producciones. En la educación virtual, la opción primera es que se fortalece lo letrado, porque los alumnos, al tiempo que se entrenan en lo digital, se introducen en decisiones personales que van desde aquello que será impreso o guardado como archivo, pasando por los diversos tipos de marcaciones sobre lo leído, para avanzar en las propias elaboraciones. Sin embargo, al mismo tiempo, también los medios hacen su juego y los estudiantes aprehenden/ aprecian imágenes o audios e intervienen subiendo sus propias elecciones o a través de sus observaciones.

De esta manera, se acerca a los docentes a las prácticas de sus alumnos tamizadas por la especificidad de la formación docente y de la identidad dada por la diferencia de edad, puesto que tanto docentes como estudiantes están atravesados por hábitos culturales de consumo que, a pesar de ser diferentes en sus contenidos, están caracterizados por ser múltiples. 
Siguiendo a García Canclini (2007), quien considera que las formas de relacionarse con los productos culturales producidos por la sociedad ha cambiado sustancialmente a partir de la llegada de las tecnologías digitales y de las fusiones entre empresas dedicadas a producir libros, mensajes audiovisuales y electrónicos, las personas son, al mismo tiempo, lectores, espectadores e internautas. Desde nuestra perspectiva, los docentes, sin reconocerlo concientemente y más allá de una sensibilidad que sacraliza el libro, también está comenzando a participar de esta transición cultural.

\section{Bibliografía}

BERARDI, Franco. (2007) Generación post-alfa. Patologías e imaginarios en el semiocapitalismo. Buenos Aires: Tinta limón.

CASTELLS, Manuel. (1995) La ciudad informacional: tecnologías de la información, reestructuración económica y el proceso urbano regional. Madrid: Alianza Editorial.

GARCÍA CANCLINI, Néstor. (2007) Lectores, espectadores e internautas. Barcelona: Gedisa.

SIBILIA, Paula. (2008) La intimidad como espectáculo. Buenos Aires: Fondo de Cultura Económica. 